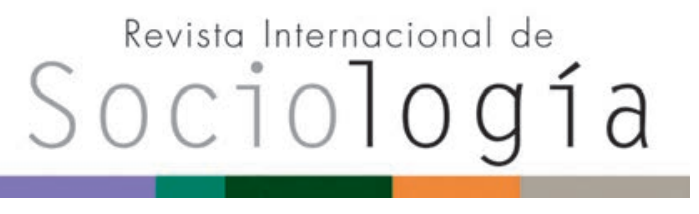

Revista Internacional de Sociología RIS

vol. 76 (3), e101, julio-septiembre, 2018, ISSN-L:0034-9712 https://doi.org/10.3989/ris.2018.76.3.16.179

\section{LA INFLUENCIA DE LA SITUACIÓN Y EL ENTREVISTADOR EN LA EXPRESIÓN DE LA IDENTIDAD PERSONAL}

\author{
Modesto Escobar \\ Universidad de Salamanca \\ modesto@usal.es \\ ORCID iD: https://orcid.org/0000-0003-2072-6071 \\ JuAn Carlos ReVILLA \\ Universidad de Salamanca \\ jcrevilla@cps.ucm.es \\ ORCID iD: https://orcid.org/0000-0001-6828-161X
}

\author{
MARINA SÁnchez-SiERRA \\ Universidad de Salamanca \\ marinasasie@gmail.com \\ ORCID iD: https://orcid.org/0000-0002-7918-3676
}

Cómo citar este artículo / Citation: Escobar, M., J. C. Revilla y M. Sánchez-Sierra. 2018. "La influencia de la situación y el entrevistador en la expresión de la identidad personal". Revista Internacional de Sociología 76(3): e101. https:// doi.org/10.3989/ris.2018.76.3.16.179

\begin{abstract}
Resumen
Este artículo se centra en la identidad personal expresada de modo abierto a través del TST (Twenty Statements Test) y demuestra la alta influencia de la situación y del entrevistador en la definición que los sujetos dan de sí mismos. Se presentan dos muestras de la población española con un total de 2.591 entrevistas, a las que se ha aplicado este instrumento en hogares, mediante entrevistador y mediante aplicación informática. El análisis compara el número de sentencias y tres indicadores: subjetividad de los enunciados, anclaje grupal con el que se identifica el individuo en su definición y atribución o rasgos personales con los que la persona se caracteriza. Se concluye que la situación y el entrevistador tienen una alta influencia en la subjetividad de las respuestas, mientras que la edad de quienes se autodefinen, en consonancia con las tesis de la individuación, tiene influencia positiva en el anclaje y negativa en la atribución.
\end{abstract}

\section{Palabras Clave}

Auto-identidad; identidad social; interaccionismo simbólico; Twenty Statements Test.

\section{THE INFLUENCE OF THE SITUATION AND THE INTERVIEWER IN THE EXPRESSION OF PERSONAL IDENTITY}

Copyright: (c) 2018 CSIC. Este es un artículo de acceso abierto distribuido bajo los términos de la licencia de uso y distribución Creative Commons Reconocimiento 4.0 Internacional (CC BY 4.0).

Recibido: 14/12/2016. Aceptado: 12/02/2018

\section{ABstract}

This article focuses on the personal identity expressed through open answers via the TST (Twenty Statements Test) and corroborates the high influence of the situation and the interviewer in self-definitions. Summing up to 2,591 subjects, two different samples have been extracted, to which this instrument has been applied in homes, through an interviewer and through computer application. The analysis compares the responses in number of sentences and in three indicators: subjectivity of the sentences, group anchorage with which the individual is identified in its definition, and attribution or traits with which the subjects are defined using three indicators: subjectivity, anchorage and individualization. It is concluded that the situation and the interviewer have a high influence on the subjectivity of the answers, while the age of those who define themselves, has a positive influence on the anchorage and negative on the attribution in consonance with the theses of individuation.

\section{KEYWORDS}

Self-identity; social identity; symbolic interactionism; Twenty Statements Test. 


\section{INTRODUCCIÓN}

La cuestión de la identidad ha sido abordada desde diferentes perspectivas en la teoría psicológica y sociológica, por lo que se ha convertido en un concepto polisémico. Existe una posición dominante en la psicología cognitiva según la cual la identidad es permanente, equiparándola con la mismidad de la persona. Esta posición supone entender la identidad en términos esenciales, como la de un sujeto autocontenido que tiene una identidad por descubrir, con libertad de acción y de transformación de la realidad, lo que ha sido cuestionado por numerosos autores (Sampson 1989; Gergen 1991). La crítica a esta posición ha venido desde perspectivas distintas y tiene en común el entender la identidad no como una entidad estática, sino como algo que se reconstruye a lo largo del ciclo vital. De hecho, los cambios identitarios que experimenta cualquier sujeto a lo largo de su vida hacen inevitable su justificación ante las personas con las que interactúa. Hay, además, presiones en la interacción social hacia la estabilidad, en la medida en que los cambios experimentados pueden poner en cuestión los compromisos adquiridos con los otros interactuantes a partir de las identidades pasadas, con las que el sujeto necesariamente se involucra (Goffman 1959). Las personas necesitamos, igualmente, una cierta continuidad en los sujetos con los que establecemos relaciones para saber a qué atenernos y qué esperar de los distintos encuentros sociales. Por estas razones, el cambio identitario supone siempre una cierta tensión para el sujeto y su entorno.

Pero no es solamente la transformación de la identidad lo que está en cuestión. Igualmente, ese carácter autocontenido implica una concepción netamente individual del sujeto que se sitúa en las antípodas de un número importante de perspectivas que han enfatizado el carácter social de la identidad personal. El interaccionismo simbólico desde Mead (1934) ya situó esta cuestión en el centro de la vida subjetiva, entendiendo que la autoconciencia del sujeto aparece a partir de la adopción de las actitudes de los otros hacia él o de la sociedad en su conjunto (el otro generalizado). Planteamientos más recientes enfatizan, igualmente, esa presencia de los otros en la propia subjetividad, bien constituyendo una especie de yo extendido (James 1890; Hermans et al. 2016) o distribuido (Hermans y Gieser 2012), dialógico (Bajtin 1986) o narrativo (Bruner 1990; Ricoeur 1990).

En este trabajo se parte de la hipótesis de que la identidad es una realidad existente que se encuentra en continua construcción y no una entidad estable preconfigurada. La identidad es construida a través de múltiples opciones de elección que enfrenta el individuo, quien, durante el proceso de socialización, adquiere conciencia del tiempo y empieza a conocer la alteridad y a adscribirse a ciertos grupos sociales (Wagner 2001).
En este sentido, es relevante señalar cómo numerosos autores coindicen en describir nuestra sociedad como de cambio acelerado, no solo en términos sociales, sino también en cuanto a las transformaciones subjetivas. Gergen (1991) considera la disolución de la identidad en las relaciones, como fruto de la saturación (multiplicación) de las relaciones sociales. Sin embargo, Sennett (1998) relaciona la corrosión del carácter que se estaría produciendo en muchos sujetos contemporáneos con los cambios en las relaciones sociales, que dificultan que el sujeto se comprometa con su entorno social, en la medida en que este es extremadamente cambiante, lo cual facilitaría, a su vez, las transformaciones identitarias.

No obstante, no parece que esta disolución se esté produciendo. Entendemos que, dentro de su dinamismo, la identidad mantiene, aún hoy, una cierta continuidad y coherencia que permite dotar de sentido a la narración del sí mismo, por los distintos anclajes que impiden de diferente modo su disolución (Revilla 2003) y cuyos efectos resultan difíciles de minar en sus efectos. No obstante, "la unidad y la continuidad no se adquieren nunca, sino que constituyen tipos espacio-temporales virtuales, formas simbólicas más o menos discernibles" (Dubar 2002:258).

Por otro lado, resulta complicado, y más en sociedades complejas como la nuestra, pensar en la identidad personal en singular. Dicho de otro modo, la identidad personal es siempre múltiple, esto es, presenta facetas bien diferenciadas que dan lugar a manifestaciones distintas del yo y, por tanto, a distintas identidades (Revilla 1998). Podríamos relacionar este carácter múltiple de la identidad con las distintas situaciones interactivas a las que nos enfrentamos en nuestra vida cotidiana, y a las que tratamos de adaptarnos para lograr transmitir la imagen personal mejor posible (McCall y Simmons 1978). En esas situaciones los sujetos desempeñamos, actualizamos y personalizamos determinados roles que hacen posible la encarnación en el sujeto de distintas identidades sociales (Goffman 1959). Dicho de otro modo, el actor se identifica con los tipos de comportamiento objetivados socialmente (roles siempre actualizados y personalizados), dando lugar al "yo social" (Berger y Luckmann 1966). Por tanto, las identidades sociales sólo cobran sentido cuando la interacción concreta las hace pertinentes, por lo que el autorreconocimiento es necesariamente fragmentario (Habermas 1990), con una integración no más que suficiente para cubrir los requerimientos culturales tematizados en la interacción. La obligación de compatibilizar relatos de identidad proviene de la interacción social, lugar donde es posible que aparezcan ciertas discordancias que la persona habrá de intentar integrar (Billig 1987). Esta integración es normalmente parcial y viene exigida por las normas culturales de la interacción social, exigencia contextualizada de coherencia entre las diversas interacciones en las que participa cada persona. 
De este modo, en la medida en que las distintas identidades sociales que una persona puede sostener en sus numerosas interacciones en los diferentes ámbitos sociales no presenten algún tipo de contradicción, no tendrá dificultad para reconocerse a sí misma en aquellas, en cuanto manifestaciones diferenciadas de su identidad que incluso podrían entenderse como elementos enriquecedores de la propia subjetividad.

Aun en esta multiplicidad identitaria, las personas mantenemos un sentimiento consciente de singularidad personal que nos hace sentir diferentes de los otros y, por ende, únicos; la consciencia de un yo que permanece en el tiempo desde el pasado y hacia el futuro, es decir, la idea de ser la misma persona siempre a pesar de los cambios que experimentamos. Asimismo, el sujeto se sostiene también en la pertenencia a grupos con los que compartimos ciertas características. En efecto, durante la socialización nos adherimos a grupos sociales, situándonos en el espacio social. Aquí las posibilidades de elección se dan en relación con grupos, pero también con actividades cotidianas del individuo. Sabemos decir cuál es nuestra pertenencia grupal y señalar qué tenemos en común con esos grupos en particular, lo que a la vez nos distingue de otros grupos. Pero para reconocer la existencia de tales grupos es preciso ser consciente del otro y de la alteridad que nos confiere (Mead 1934; Ricoeur 1990), pues la distinción y el reconocimiento juegan un importante papel, al validar lo que Revilla (2003: 62) designa como pretensión identitaria, es decir, lo que mostramos o queremos mostrar que somos.

Desde aquí podemos diferenciar las dos caras del concepto de identidad: la identidad personal, relacionada con el sentimiento de unicidad y diferenciación; y la identidad social, relacionada con la pertenencia (Goffman 1963; 1967). En cuanto a la autodefinición, Gómez y Vázquez (2015) señalan que los atributos idiosincráticos personales aluden a la identidad personal y, por su parte, las alusiones a afiliaciones a grupos o categorías (lo que aquí más tarde denominaremos referencias y anclajes) se enmarcan dentro de la identidad social. A tales grupos se otorgan tanto unos rasgos distintivos que diferenciarán a quienes forman parte del mismo, como una valoración positiva, razón por la cual el individuo se sentirá o aspirará a ser parte de los grupos con los que se identifica (Deschamps y Devos 1996).

Si leemos esta diferenciación entre identidad personal e identidad social desde la tesis de la individualización (Giddens 1991; Habermas 1990), podríamos pensar que los seres humanos pondremos cada vez más empeño y energía en la construcción de nuestro yo personal, en la medida en que las condiciones de la modernidad hacen más imperiosa la construcción de la propia identidad individual, del yo como proyecto reflejo (Giddens 1991), de cuya construcción y re- construcción es responsable cada individuo, al tiempo que las identidades colectivas son más difíciles de sostener (Beck y Beck-Gernsheim 2001). Como dice Habermas (1990), al sujeto se le exigen cada vez mayores cotas de individuación que den lugar a una identidad postconvencional caracterizada por la autodeterminación y la autorrealización.

Dada la pluralidad de manifestaciones de la identidad personal, no habría de sorprender que la expresión de la identidad tuviera un claro componente situacional. Esto es, que la imagen que los sujetos presenten de sí sea distinta en diferentes contextos o situaciones, sin que ello implique que pudiéramos entender unas imágenes como más auténticas o verdaderas que otras. Supondría simplemente destacar algunos elementos identitarios sobre otros, en la medida en que cada situación concreta hace que algunos aspectos de la identidad personal sean más relevantes que otros. Este situacionismo de la identidad no es ajeno al interaccionismo simbólico en general, en cuanto encaja bien con la teoría de rol: dado que en cada situación social se desempeñan roles particulares, las manifestaciones del sujeto son también específicas a esa situación (Goffman 1959). McCall \& Simmons (1978) incluso se refieren al yo situacional (situational self), que depende de la importancia relativa (salience) de las diferentes identidades en cada interacción social. El subconjunto de identidades salientes en una interacción constituye el personaje del individuo en la situación.

A este respecto, Goffman (1959) señala que cuando nos presentamos a nosotros mismos, los demás quieren, mediante esa presentación, organizar el contexto en el que nos encontramos, así como ordenar las expectativas que pueden generarse hacia el sujeto que se presenta y las que este puede crearse hacia nosotros. Hasta muy recientemente, este proceso era relativamente sencillo, en tanto todas nuestras interacciones se realizaban cara a cara, conociendo gran cantidad de características de nuestro interlocutor antes incluso de que hubiera comunicación oral, gracias a la imagen física y a la comunicación no verbal.

Sin embargo, con el desarrollo de los medios de comunicación (radio, televisión y, con mayor fuerza actualmente, Internet) las interacciones han mudado de naturaleza. Las nuevas tecnologías posibilitan que interaccionemos con un número cada vez más amplio de individuos, sumergiéndonos progresiva e inexorablemente en el mundo social y dejándonos expuestos a las opiniones y valoraciones de los demás, pero también a sus estilos de vida. Para Gergen (1991: 96), "la vida contemporánea es un mar turbulento de relaciones sociales". En particular, Internet es, al mismo tiempo, una puerta por la que entra información elegida por el sujeto y un portal donde exponerse y presentarse al mundo, caso en el cual puede elegirse dónde hacer esta presentación (red social, red social 
de carácter profesional, blog, página web personal, etc.) y a qué público queremos llegar.

Con todo lo dicho, podemos entender que, siendo el cuerpo un elemento constitutivo de quienes somos, la imagen que damos de nosotros mismos y, con ello, nuestra autodefinición no será la misma en entornos físicos que en entornos virtuales. En estos últimos el cuerpo queda fuera y nuestro público potencial es desconocido e imaginado, y no tiene ningún dato sobre nosotros.

En este sentido, la utilización de un instrumento que permita acceder con facilidad a estas manifestaciones múltiples de la identidad, como es el caso del Twenty Statements Test (TST), nos permitiría dar sentido a este aspecto tan característico de la identidad humana. Los ya sesenta años que se han cumplido desde su primer uso (Kuhn y McPartland, 1954) nos proporcionan bastante información sobre sus posibilidades, aunque queden aún algunas cuestiones que requieran más investigación. Posteriores investigaciones pusieron de manifiesto, fundamentalmente, el predominio de respuestas idiocéntricas (o individuales) frente a las alocéntricas y grupales; así como las diferencias culturales existentes en las respuestas de sujetos pertenecientes a culturas más individualistas (mayor porcentaje de respuestas idiocéntricas) respecto de aquellas de sujetos de culturas más colectivistas (con mayor número de respuestas alocéntricas y grupales; ver por ejemplo Trafimow, Triandis y Goto 1991). Investigaciones posteriores se han preguntado cómo las circunstancias o condicionantes de administración de la prueba pueden influir sobre el resultado. Algunos (Gardner, Gabriel y Lee 1999; Trafimow, Triandis y Goto 1991) han conseguido aumentar el porcentaje de respuestas independientes (idiocéntricas) experimentalmente mediante estímulos individuales (y viceversa); otros han logrado provocar más respuestas interdependientes en personas occidentales estimulando sentimientos positivos (Ashton-James et al. 2009). De modo más interesante para nuestro trabajo, aunque con un uso distinto del TST, Emanuel et al. (2014) han señalado cómo las personas tienden a mostrar más información privada (realmente tienden a retirar menos información privada de sus respuestas al TST, según el procedimiento investigador) cuando se trata de un encuentro cara a cara, mientras que se muestra menos información privada en un espacio genérico (no específico) de la red y todavía menos en contextos más específicos de Internet, como una cita amorosa o una entrevista de trabajo.

En nuestro caso, la comparación entre diferentes formatos de administración de la técnica nos puede permitir indagar sobre el contexto situacional de la identidad, en concreto sobre las imágenes específicas que podemos dar de nosotros mismos en entornos virtuales frente a los que damos en entornos cara a cara.

\section{Planteamiento del trabajo}

Partiendo de la premisa de que el contexto o la situación pueden determinar diferentes formas de definición del sí mismo, este texto centra la atención en el concepto de autoidentidad como definición de uno mismo. Para ello, se realiza una comparación de las autodefiniciones dadas en dos situaciones. En la primera, los entrevistados se encuentran en su hogar y en presencia de un entrevistador o entrevistadora; mientras que, en la segunda, pueden encontrarse en el lugar que prefieran, pero sin entrevistador presente, ante un ordenador, y pueden proferir su autodefinición en el momento que más les convenga." Estos dos modos de aplicación nos permiten estudiar las semejanzas y diferencias de las definiciones que damos de nosotros mismos según la situación en las que hayan sido realizadas.

Ambas aplicaciones se hicieron de modo anónimo. En cambio, las situaciones diferían dado que, cuando un entrevistador o entrevistadora acudía a un hogar, la persona que respondía a las preguntas mostraba al visitante no sólo sus características físicas, sino también las de su hogar; mientras que quien completaba sus respuestas en entorno virtual no tenía a nadie observándole al contestar, aunque pudiera ser consciente o sospechara que la empresa que le seleccionaba conocía gran parte de su información personal, por su inclusión en un panel para la realización de estudios comerciales y de opinión pública.

\section{Metodología}

\section{Muestra}

Se recogió información de dos muestras que denominaremos $E$ y $W$, donde $E$ es la conformada por personas que realizaron el TST en sus hogares mediante entrevistador y $\mathrm{W}$ la muestra de aquellos que respondieron al cuestionario por Internet en un ordenador. En ambas se trabajó sobre un universo conformado por personas residentes en España (excepto Ceuta y Melilla), con una edad comprendida entre los 18 y los 70 años y que hablaran castellano.

Para la obtención de la muestra $\mathrm{E}$, se elaboró un muestreo mediante rutas aleatorias controlando cuotas de sexo, edad y comunidad autónoma de residencia. Se realizaron 146 rutas, en las que 54 entrevistadores aplicaron 1.007 encuestas válidas, superando la previsión inicial de 1.001. En esta muestra, el error muestral fue del $+/-3,1 \%$, dado el supuesto de selección aleatoria simple. La relación de género es 1:1, la edad media es de 42 años y, del total, tenían estudios superiores completados el $24 \%$.

En la muestra W, los participantes respondieron una entrevista online enviada por correo electrónico de modo voluntario, con un incentivo pequeño por la 
participación consistente en un bono canjeable valorado en $0,40 €$. Se completaron en esta aplicación un total de 1.584 entrevistas, con un error muestral del $+/-2,5$ en el supuesto de aleatoriedad simple. En la encuesta participaron un $47,9 \%$ de mujeres y un $52,1 \%$ de hombres con una edad media, en conjunto de 37 años. El 44,3\% de los que contestaron a esta encuesta declararon poseer estudios universitarios. El sesgo de esta característica es más que evidente, por lo que se realizó un análisis estadístico para eliminarlo, como se detallará más adelante.

\section{Instrumento}

La herramienta utilizada para la recogida de datos fue el ya mencionado TST, seguido de un breve cuestionario que recogía aspectos relacionados con identidad, relación mantenida con grupos o asociaciones, escala de post-materialismo, preguntas sobre política económica, así como características sociodemográficas de las personas que conformaban la muestra, incluyendo lengua principal que hablaban, proximidad política y datos familiares, laborales y de carácter económico.

EI TST consiste en presentar a los participantes una sola pregunta, “¿quién soy yo?", dándoles un espacio y tiempo determinados para responder. Como ya se ha indicado, este instrumento ha sido ampliamente aplicado, especialmente a estudiantes, para examinar la interconexión entre cultura e identidad (Carpenter y Meade-Pruitt 2008; Eaton y Louw, 2000). Múltiples han sido los estudios de identidad realizados empleando el TST, especialmente los inspirados en los estudios de las dimensiones culturales de Hofstede (1980) y en su descripción de la cultura individualista como aquella tendente a centrarse en la persona, en comparación con la cultura colectivista, centrada en el grupo. Como muestra de sus diversas aplicaciones, pueden citarse los trabajos de Schwirian (1964), Driver (1969), McPartland (1971), Escobar (1983; 1987); Noppe (1983), Greenwald y Pratkanis (1984), Triandis (1989), Trafimow, Triandis y Goto. (1991), Dhawan et al. (1995), Lalljee y Angelova (1995), Trafimow et al. (1997), Watkins y Gerong (1999), Eaton y Louw (2000), Somech (2000), Kanagawa, Cross y Markus (2001), Grace y Cramer (2002), Del Prado et al. (2007), Santamaría et al. (2010), Vindhya (2012), Isbell et al. (2013) y Lam et al. (2014).

En las dos muestras en consideración, la primera pregunta fue el propio TST, donde se solicitaba a los encuestados que escribieran una breve descripción de sí mismos, sin más instrucciones y, para ello, en el caso de los hogares se les daba una hoja en blanco con 20 líneas numeradas. La pregunta estaba en el encabezado de la hoja, redactada del siguiente modo tras haber realizado un estudio piloto para testarla:
"Para este estudio necesitamos que nos hable de $V d$., que se describa, que nos diga quién y cómo es, o cómo se ve a sí mismo. Utilice, por favor, el espacio reservado y escriba todas las respuestas que se le ocurran a la pregunta quién soy yo. No se trata de pensar mucho, queremos que nos escriba con sus propias palabras lo primero que se le ocurra."

En el caso de los cuestionarios aplicados vía web, la pregunta se redactó de modo similar. Para responder contaban con veinte espacios de una longitud equivalente a la pantalla en la que escribían sus respuestas:

"Esta vez queremos que nos hable de Vd., que se describa como persona. Para ello nos gustaría que nos escribiese veinte respuestas que se le ocurran sobre Vd. a la pregunta quién soy yo. No se trata de pensar mucho las respuestas, sino de decirnos lo primero que se le viene a la cabeza y contestar rápidamente."

Tras esta primera cuestión, estaba el resto del cuestionario, con otras cuatro preguntas relacionadas con temáticas de identidad, asociacionismo y valores, y otras catorce sociodemográficas (género, edad, origen, estructura familiar, nivel de estudios, situación laboral, valores, identidad política y lenguas habladas). En el cuestionario aplicado a hogares se intercalaron siete preguntas sobre política económica y dos preguntas sobre ingresos mensuales personales y familiares. En cualquier caso, como todas estas preguntas se formularon después de aplicar el TST, su influencia sobre el instrumento ha de ser considerada nula.

\section{Codificación del TST}

Al tratarse de respuestas abiertas, es preciso realizar una labor de codificación que haga las respuestas agrupables y comparables. En este caso, ambas muestras han seguido los mismos criterios de codificación y han sido tratadas con el programa de análisis cualitativo Atlas.ti, para después ser analizadas estadísticamente.

El sistema de codificación utilizado parte de tres criterios diferentes y compatibles de codificación: sentido, referencia y atributo, siguiendo la línea de otros estudios sobre identidad mediante aplicación del TST, como los clásicos de McPartland (1971), Kuhn y McPartland (1954); el de Rhee et al. (1995), que establece ocho categorías con 33 subcategorías aplicadas a la diferenciación entre culturas individualistas y colectivistas; el utilizado por Escobar y Román (2011) para el estudio de la autodefinición en Internet, o el más reciente estudio de Escobar, Montes y Sánchez-Sierra (2015) para descripciones personales con entrevistador.

\section{Sentido}

El sentido recoge el contenido de cada sentencia (oración) enunciada por la persona entrevistada. Es 
el qué se dice. El sentido es el criterio más utilizado para analizar las respuestas al TST desde que Kuhn y McPartland (1954) lo establecieran. Estos autores dividían las sentencias en dos grupos: consensuales y subconsensuales (Véase figura 1). Las primeras se consideran objetivas, pues el significado que quiere dar a entender el emisor es entendido inmediatamente por el receptor sin necesidad de explicaciones adicionales, y están relacionadas con aspectos comprobables y no tanto con opiniones o valoraciones. Dentro de los roles consensuales encontramos:

\begin{abstract}
"los enunciados sobre posición social del sujeto y sobre los roles que de ella se derivan, incluyendo enunciados de categorías sociales, tales como nombre, edad, afiliación religiosa, relaciones de parentesco, etnias, nacionalidad, pertenencia a otros grupos formales o informales y también respuestas sobre características físicas del sujeto" (Kuhn, citado en Schwirian 1964).
\end{abstract}

Dentro de las categorías consensuales se contemplan seis subcategorías: física (aspectos físicos objetivos), propiedad (si se habla de cosas materiales que se poseen), actividad (hábitos o costumbres, sin valorar si le gustan o no, o cuánto), colectiva (pertenencia grupal general: profesional, religiosa, territorial,...), relato (cuando habla en forma narrativa sobre hechos del pasado) y global consensual (afirmaciones que no aportan información sobre esa persona particular, pues son válidas para cualquier persona).

Por su parte, los enunciados subconsensuales sí necesitan ser explicados por el emisor para su correcta interpretación, por ser subjetivos. Aquí están "las especificaciones del modo de ser o preferir de los sujetos" y "aquellos asertos del individuo que proporcionan una información tan vaga que no se puede hacer ninguna inferencia sobre su comportamiento" (McPartland 1971).
Entre los enunciados subconsensuales se encuentran cinco subcategorías importantes: autoevaluación (cualquier tipo de evaluación que cada persona da de sí misma y de su carácter y que, a su vez, pueden ser de tipo intelectual, práctica, de carácter o moral, social, estética o anímica), autoestima (valoración que la persona hace de sí misma), preferencia (otorga primacía a algo, incluyendo gustos personales); creencia (opina o valora realidades externas) y aspiración (conjeturas o deseos sobre el futuro).

También dentro de la categoría subconsensual se incluyen otras categorías menores: las indefiniciones, sentencias caracterizadas por ser poco clarificadoras que, a su vez, agrupan enunciados que expresan duda o desconocimiento de la persona hacia sí misma; alienación de quien responde; metáforas utilizadas para la autodefinición; sentencias que hablan sobre otras personas o realidades, y evasivas del test, que rellenan un espacio pero sin aludir a la pregunta.

\section{Referencia}

Las referencias son los elementos que componen los enunciados, independientemente del sentido que se les dé. Podríamos considerar la referencia como la entidad o conjunto de entidades que se mencionan explícitamente en una frase en modo de sintagma nominal. Es decir, no importa cómo se expresa, sino qué, con independencia de si se hace de forma positiva o negativa.

La división de referencias en subcategorías podría ser enormemente amplia. No obstante, aquí se sigue la presentada en la figura 2 basada en estudios previos mediante el análisis de millares de respuestas. Así, se llega a un total de 26 códigos recogidos en seis subcategorías: biosociales (rasgos objetivos y físicos), familiares (lugar que se

Figura 1.

Esquema jerárquico de las categorías de sentido con ejemplos en cursiva.

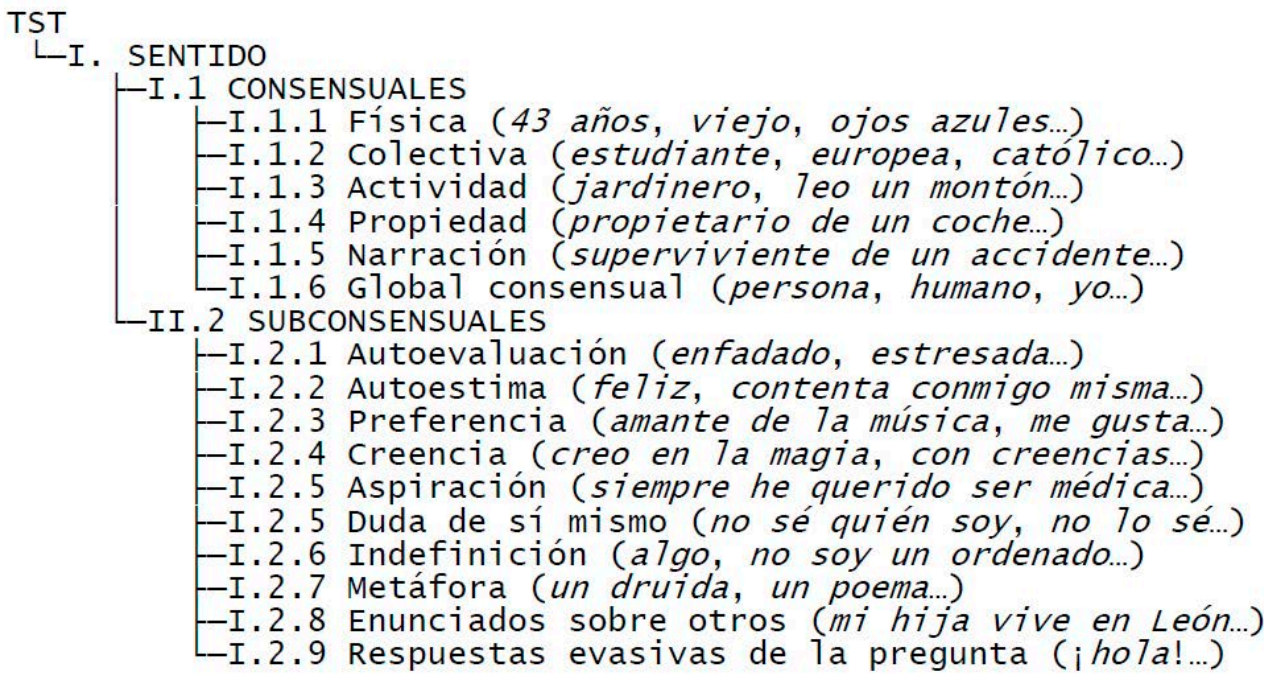


ocupa dentro de la familia o mención a miembros de la misma), grupales (grupo primario no familiar, grupos secundarios, u otras pertenencias grupales), activas (roles laborales, de estudios o actividades de ocio y tiempo libre), sociales (referencias sociales no relacionadas con grupos con los que la persona tiene un vínculo, sino con colectivos más amplios e impersonales) y genéricas (no dan información específica de quién contesta, al ser aplicables a cualquier individuo).

\section{Atributo}

El atributo complementa al sujeto de la oración dando información sobre sus cualidades o propiedades. Por lo general se trata de un adjetivo, pero hay casos en los que un sustantivo puede tener esta función, como en la afirmación "soy padre", con la que se especifica un rol social y un lugar dentro del grupo primario familiar, pero a la vez se está mostrando que este rol es importante para la persona entrevistada. En estos casos el sustantivo suele aparecer solo.

Este criterio de codificación puede subdividirse operativamente en tres categorías, como se refleja en la figura 3: el calificativo se compone de los adjetivos propiamente dichos y puede categorizarse del mismo modo que se hizo con las autoevaluaciones; el atributo nominal, es decir, un sustantivo con una función gramatical atributiva, que ha de categorizarse como referencia; y el externo, cuando aparece un calificativo que no hace referencia a la persona que habla, sino a otras personas o cosas. Esta última categoría no posee otra utilidad en el análisis que la de no considerar determinados adjetivos que aparecen en las respuestas como propios de la imagen de la persona que se describe a sí misma.

\section{Indicadores e hipótesis}

A partir de las categorías anteriormente descritas se han construido cuatro índices para analizar las diferencias de las respuestas según los contextos.

1. Sentencias: El número de enunciados que cada persona emite sobre sí mismo. La hipótesis es que quienes responden ante un ordenador emiten un mayor número de sentencias. De igual modo, se espera que personas con más estudios profieran mayor número de respuestas.

2. Subjetividad: Se construye restando las respuestas objetivas (consensuales, I.1 en la figura 1) a las respuestas subjetivas (subcon-

Figura 2.

Esquema jerárquico de las categorías de referencia con ejemplos en cursiva.

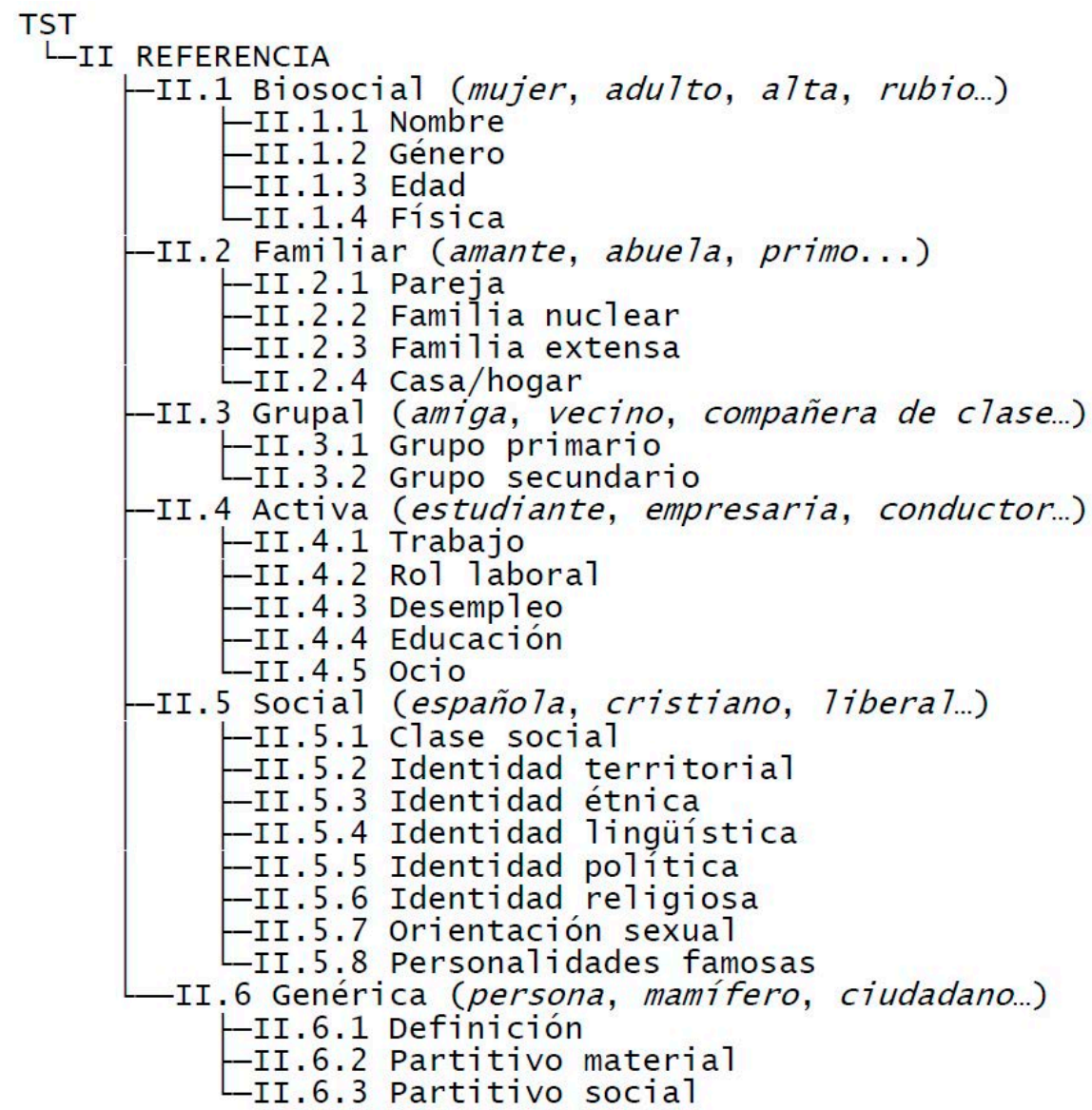


Figura 3.

Esquema jerárquico de las categorías de atribución con ejemplos en cursiva.

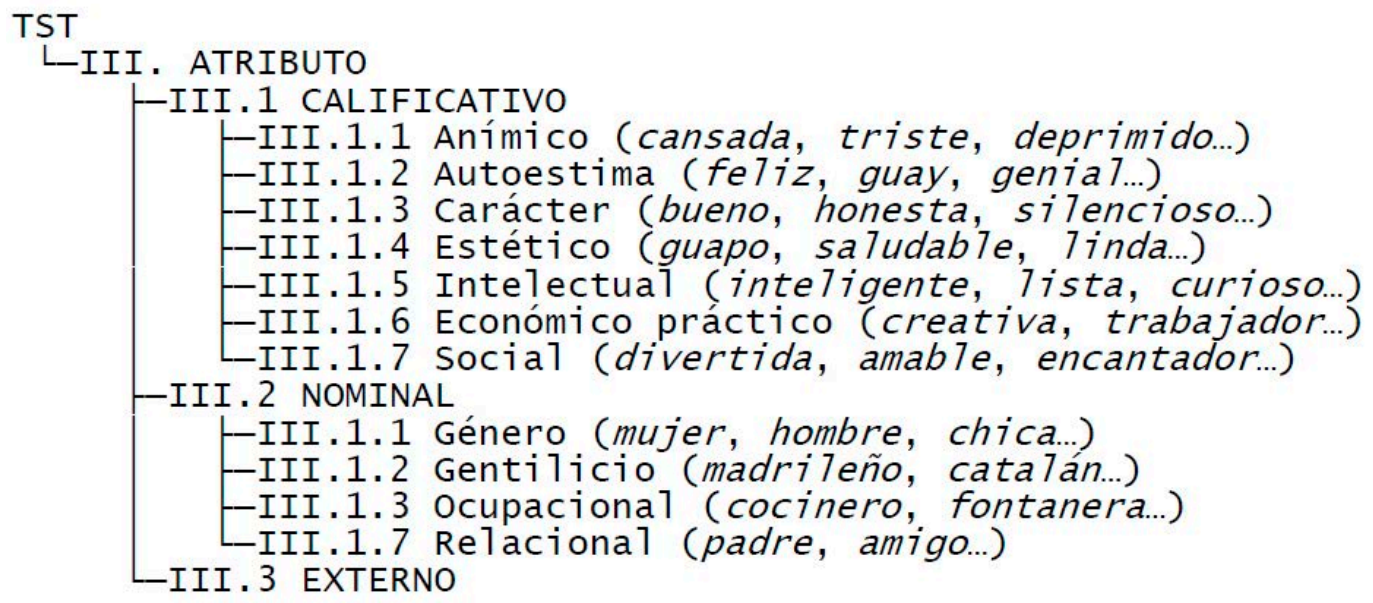

sensuales, I.2 en la figura 1) y dividiendo por el número total de enunciados emitidos. En consecuencia, un valor negativo corresponde a aquellas personas que contestan con más respuestas objetivas. Sobre este criterio cabría esperar mayor porcentaje de respuestas subjetivas entre quienes contestan ante un entrevistador, pues no necesitan contextualizarse objetivamente. Inversamente, las personas mayores proferirán menos enunciados subjetivos, al haber vivido una identidad más estable familiar y laboralmente.

3. Anclaje: Es el resultado de dividir las referencias familiares, grupales, activas o sociales (II.2, II.3, II.4 y II.5 en la figura 2) por el número de sentencias. Posiblemente quepa esperar un número similar de referencias de anclaje que de atribuciones por enunciado. A mayor edad también es esperable mayor número de referencias, no solo por la acumulación de experiencias, sino también por haber vivido momentos en los que los vínculos sociales eran más permanentes y esenciales en la configuración de la personalidad.

4. Atribución: Se considera que contestar con atributos personales (III.1 en la figura 3 ) es una manifestación de la progresiva individualización que conlleva la modernidad. Para ello, puede resultar útil emplear como indicador el porcentaje de adjetivos calificativos que emite cada persona sobre el total de enunciados. Complementariamente con la anterior hipótesis, vivir en núcleos urbanos pequeños y tener mayor edad implicaría menor grado de atribución en las respuestas.

Además de las anteriores, la hipótesis más central en este artículo es que estos indicadores presentan valores diferentes según el modo de aplicación del TST.

\section{AnÁlisis y Resultados}

Si se observan únicamente las medias de estos indicadores por modalidad de aplicación, pueden detectarse los siguientes datos: a) las respuestas abundan más entre quienes contestan con ordenador $(15,5$ vs. 10,7$)$; b) hay mayor tendencia a la subjetividad que a la objetividad en las respuestas a la pregunta "¿quién soy yo"?, pues en las dos condiciones estudiadas el indicador presenta resultados positivos; c) la carga de subjetividad es mayor ante un entrevistador $(72,6 \%)$ que ante un ordenador $(35,1 \%)$; d) hay un porcentaje mayor de atributos $(65,2 \%)$ que de referencias de anclaje $(33,9 \%)$, especialmente ante un entrevistador, pues en estas circunstancias hay una muy alta propensión a la individualización o atribución (72,9\%); e) la desviación típica en número de sentencias y porcentaje de atribución son similares entre contextos. Sin embargo, ante un entrevistador hay mayor dispersión en el indicador de anclaje y menor en el de subjetividad.

Ahora bien, estas medias podrían estar sesgadas por cuanto la muestra que rellenó el test por ordenador se ha autoseleccionado, con una tasa de respuesta del $37,5 \%$, a partir de un panel representativo de la población con recursos electrónicos. Para comprobar y evitar estos sesgos, se han realizado regresiones introduciendo variables sociodemográficas (género, edad, nivel de estudios, situación laboral, hábitat y preferencias partidistas), además del grado de participación en asociaciones y de la opinión sobre cuál se considera el ingrediente fundamental de la identidad personal. Tras estas regresiones se obtuvieron las medias ajustadas de cada una de las situaciones controladas por las características de la población. Como puede comprobarse en la tabla 1, las diferencias entre las medias brutas y las medias ajustadas no superan las ocho décimas en ninguno de los casos. 
Tabla 1.

Medias de los índices según contexto

\begin{tabular}{|c|c|c|c|c|c|}
\hline & & \multicolumn{2}{|c|}{ Situación } & \multirow{2}{*}{\multicolumn{2}{|c|}{ Total }} \\
\hline & & Entrevistador & Ordenador & & \\
\hline \multirow{2}{*}{ Número de sentencias } & Media & $10,7(10,7)$ & $15,5(15,4)$ & 13,6 & $\left({ }^{* * *}\right)$ \\
\hline & D. típica & 4,8 & 6,2 & 6,2 & \\
\hline \multirow[t]{2}{*}{$\%$ de subjetividad } & Media & $72,6(72,0)$ & $35,1(35,1)$ & 49,8 & $\left({ }^{* * *}\right)$ \\
\hline & D. típica & 36,0 & 53,6 & 50,9 & \\
\hline \multirow[t]{2}{*}{$\%$ de anclaje } & Media & $45,1(45,4)$ & $26,6(27,3)$ & 33,9 & $\left({ }^{\star \star \star}\right)$ \\
\hline & D. típica & 32,0 & 21,0 & 27,4 & \\
\hline \multirow[t]{2}{*}{ \% de atribución } & Media & $72,9(73,7)$ & $60,3(59,1)$ & 65,2 & $\left({ }^{* * *}\right)$ \\
\hline & D. típica & 27,0 & 28,5 & 28,6 & \\
\hline
\end{tabular}

Entre paréntesis, las medias ajustadas por los predictores de las regresiones multinivel (véase tabla 3).

$\left(^{* \star *}\right) p<.001$

Observando la primera columna de la tabla 2 y continuación, en relación con el número de sentencias se confirma la hipótesis de que quienes contestaron ante el ordenador emitieron mayor número de respuestas. De igual forma, las personas con estudios universitarios también presentaron medias mayores. De modo menos esperado, se notan los siguientes hechos: a) los hombres dan algunas respuestas menos que las mujeres y $b$ ) aquellos que han participado o participan activa o pasivamente en asociaciones son más proclives a emitir mayor número de enunciados, e igual ocurre con los votantes del Partido Popular.

Pasando al análisis de la subjetividad de las respuestas de quienes responden a la pregunta "¿quién soy yo?", es de notar el fuerte efecto de responder ante un entrevistador, pues, en este caso, las personas emiten respuestas 36,3 puntos más subjetivas. Además, como se esperaba, las personas de más edad son menos subjetivas, pero también se advierte en este aspecto la influencia de quienes piensan que la religión es lo más importante en la definición, pues presentan un significativo mayor porcentaje de respuestas objetivas.

En lo que se refiere al anclaje, se observa que quienes contestan ante un entrevistador conforman sus respuestas con más referencias ancladas que los que lo hacen frente a la pantalla. Este resultado es aparentemente contradictorio, pues las respuestas objetivas son más propensas al uso de referencias que al de atributos. De todos modos, como sugerían las hipótesis, las personas mayores se manifiestan más ancladas.

Finalmente, si se valoran los efectos sobre la proporción de atributos o adjetivos que la gente profiere al definirse a sí misma, se advierte que aquí también influye la situación en la que se responde a la pregunta "¿quién soy yo?". En este caso, se emite mayor proporción de atributos ante un entrevistador. Igualmente, de acuerdo con las hipótesis formuladas, las personas con más edad son menos propen- sas al uso de adjetivos. A esta categoría de individuos que muestran menor inclinación a mencionar atributos se puede añadir la de quienes habitan en pueblos pequeños.

Al haberse detectado la gran importancia de que el entrevistador estuviera presente, podríamos preguntarnos hasta qué punto ello es efecto espurio de las personas que interrogan o, incluso, la posibilidad de que haya influido la transcripción de las respuestas, en el caso de aquellas aplicaciones en donde no haya sido la persona entrevistada quien haya escrito las respuestas emitidas. Para corroborar esto, en aproximadamente la mitad de las entrevistas realizadas, los propios entrevistados escribieron sus respuestas y la otra mitad fue transcrita por la persona enviada por quienes plantearon la investigación.

Como muestra la tabla 3 , gran parte de la variación (efectos aleatorios) de las respuestas de quienes participaron en la encuesta reside en quienes les entrevistaron. Tal es el extremo caso del índice de anclaje, en el que la desviación típica del efecto del entrevistador representa un $80 \%$ de la desviación típica residual; y, en menor medida, en el de la subjetividad, donde supone una magnitud equivalente a más del $30 \%$ de la que posee la desviación típica residual. Mirando el conjunto de efectos vemos que, eliminado el efecto individual de los entrevistadores, la situación de entrevista personal solo repercute de modo significativo en la subjetividad. Efectivamente, cuando nos definimos ante otra persona, tenemos tendencia a emplear mayor porcentaje de rasgos invisibles o subjetivos.

Analizando los rasgos sociodemográficos, se observan con estos modelos pautas similares a las anteriores: la importancia de la edad en el anclaje y la atribución; que los hombres expresan menos enunciados sobre sí mismos (medio enunciado menos); que personas con estudios superiores son más expresivas, y que personas dedicadas a tareas domésticas lo son menos, pero en compensación dan mayor porcentaje de respuestas objetivas. 
Tabla 2.

Regresiones de sentencias, subjetividad, anclaje y atribución. Coeficientes y errores típicos.

\begin{tabular}{|c|c|c|c|c|}
\hline & Sentencias & Subjetividad & Anclaje & Atribución \\
\hline \multirow[t]{2}{*}{ Hombre } & $-0,587 *$ & $-0,517$ & 0,743 & 1,761 \\
\hline & $(0,23)$ & $(1,96)$ & $(1,07)$ & $(1,15)$ \\
\hline \multirow[t]{2}{*}{ Edad 30-39 años } & $-0,173$ & $-2,101$ & 0,696 & $-0,956$ \\
\hline & $(0,37)$ & $(3,10)$ & $(1,68)$ & $(1,81)$ \\
\hline \multirow[t]{2}{*}{ Edad 40-49 años } & $-0,339$ & $-0,633$ & 2,390 & $-1,786$ \\
\hline & $(0,38)$ & $(3,18)$ & $(1,73)$ & $(1,86)$ \\
\hline \multirow[t]{2}{*}{ Edad 50-59 años } & $-0,122$ & $-0,804$ & 2,925 & $-2,255$ \\
\hline & $(0,44)$ & $(3,72)$ & $(2,02)$ & $(2,17)$ \\
\hline \multirow[t]{2}{*}{ Edad 60-70 años } & $-0,19$ & $-11,685 *$ & $9,716^{* * *}$ & $-9,031^{* *}$ \\
\hline & $(0,58)$ & $(4,82)$ & $(2,62)$ & $(2,81)$ \\
\hline \multirow[t]{2}{*}{ Estudios primarios } & 0,146 & 1,237 & $-1,998$ & $-1,871$ \\
\hline & $(0,44)$ & $(3,65)$ & $(1,98)$ & $(2,13)$ \\
\hline \multirow[t]{2}{*}{ Estudios secundarios } & 0,447 & 0,482 & $-1,404$ & $-0,033$ \\
\hline & $(0,41)$ & $(3,45)$ & $(1,87)$ & $(2,01)$ \\
\hline \multirow[t]{2}{*}{ Estudios universitarios } & 0,890 * & 0,671 & $-2,800$ & 1,972 \\
\hline & $(0,42)$ & $(3,54)$ & $(1,92)$ & $(2,07)$ \\
\hline \multirow[t]{2}{*}{ S. laboral: Empresario } & $-0,902$ & $-6,227$ & 1,519 & $-5,908$ \\
\hline & $(1,08)$ & $(9,02)$ & $(4,90)$ & $(5,26)$ \\
\hline \multirow[t]{2}{*}{ S. laboral: Fijo } & $-0,318$ & $-1,239$ & 1,996 & 2,644 \\
\hline & $(0,51)$ & $(4,23)$ & $(2,30)$ & $(2,47)$ \\
\hline \multirow[t]{2}{*}{ S. laboral: Temporal } & $-0,178$ & $-1,848$ & $-0,367$ & 3,942 \\
\hline & $(0,55)$ & $(4,58)$ & $(2,49)($ & $(2,67)$ \\
\hline \multirow[t]{2}{*}{ S. laboral: Profesional } & 0,596 & $-3,257$ & 1,951 & 1,404 \\
\hline & $(0,60)$ & $(5,07)$ & $(2,75)$ & $(2,96)$ \\
\hline \multirow[t]{2}{*}{ S. laboral: Parado } & 0,011 & 0,622 & $-0,915$ & 0,559 \\
\hline & $(0,30)$ & $(2,55)$ & $(1,38)$ & $(1,49)$ \\
\hline \multirow[t]{2}{*}{ S. laboral: Estudiante } & 0,021 & $-10,211$ & 0,316 & $-2,339$ \\
\hline & $(0,63)$ & $(5,26)$ & $(2,85)$ & $(3,07)$ \\
\hline \multirow[t]{2}{*}{ S. laboral: T. doméstico } & $-0,613$ & $-12,648 *$ & 3,176 & $-0,276$ \\
\hline & $(0,69)$ & $(5,74)$ & $(3,12)$ & $(3,35)$ \\
\hline \multirow[t]{2}{*}{ S. laboral: Otra } & 0,067 & 3,828 & 2,617 & 1,332 \\
\hline & $(0,93)$ & $(7,75)$ & $(4,21)$ & $(4,52)$ \\
\hline \multirow[t]{2}{*}{ Voto o simpatía: PSOE } & 0,373 & 1,121 & 0,504 & 0,169 \\
\hline & $(0,33)$ & $(2,81)$ & $(1,52)$ & $(1,64)$ \\
\hline \multirow[t]{2}{*}{ Voto o simpatía: PP } & 1,052 ** & 1,315 & 1,050 & 0,327 \\
\hline & $(0,34)$ & $(2,83)$ & $(1,53)$ & $(1,65)$ \\
\hline \multirow[t]{2}{*}{ Voto o simpatía: IU } & $-0,123$ & $-5,728$ & $-0,094$ & $-1,659$ \\
\hline & $(0,46)$ & $(3,87)$ & $(2,10)$ & $(2,26)$ \\
\hline \multirow[t]{2}{*}{ Voto o simpatía: Otros } & 0,236 & $-3,088$ & 0,861 & $-1,400$ \\
\hline & $(0,33)$ & $(2,77)$ & $(1,50)$ & $(1,62)$ \\
\hline \multirow[t]{2}{*}{ Identidad = nacimiento } & 0,351 & $-2,951$ & 0,005 & 1,212 \\
\hline & $(0,30)$ & $(2,49)$ & $(1,35)$ & $(1,45)$ \\
\hline \multirow[t]{2}{*}{ Identidad = nacionalidad } & $-0,083$ & $-2,260$ & $-0,134$ & $-0,549$ \\
\hline & $(0,32)$ & $(2,69)$ & $(1,46)$ & $(1,57)$ \\
\hline Identidad = política & 0,033 & $-1,677$ & $-2,657$ & 1,515 \\
\hline & $(0,39)$ & $(3,31)$ & $(1,8)$ & $(1,93)$ \\
\hline Identidad = religión & $-1,015$ & $-9,461 *$ & 0,898 & $-3,220$ \\
\hline & $(0,52)$ & $(4,37)$ & $(2,37)$ & $(2,55)$ \\
\hline
\end{tabular}




\begin{tabular}{|c|c|c|c|c|}
\hline \multirow[t]{2}{*}{ Identidad = etnia } & 0,179 & $-0,542$ & $-2,419$ & 5,033 \\
\hline & $(0,62)$ & $(5,19)$ & $(2,82)$ & $(3,03)$ \\
\hline \multirow[t]{2}{*}{ Asociación: activamente } & $1,420 * * *$ & $-5,404$ & 2,106 & $-0,882$ \\
\hline & $(0,34)$ & $(2,83)$ & $(1,54)$ & $(1,65)$ \\
\hline \multirow[t]{2}{*}{ Asociación: pertenece } & $1,384^{* * *}$ & $-5,177$ & 3,397 & $-3,803 *$ \\
\hline & $(0,38)$ & $(3,22)$ & $(1,75)$ & $(1,88)$ \\
\hline \multirow[t]{2}{*}{ Asociación: perteneció } & 1,014 ** & $-0,866$ & 1,499 & $-1,553$ \\
\hline & $(0,38)$ & $(3,15)$ & $(1,71)$ & $(1,84)$ \\
\hline \multirow[t]{2}{*}{ Nace en capital } & 0,449 & 0,227 & $-0,17$ & 1,125 \\
\hline & $(0,29)$ & $(2,39)$ & $(1,30)$ & $(1,40)$ \\
\hline \multirow[t]{2}{*}{ Nace en pueblo pequeño } & 0,629 & $-2,580$ & 2,924 & $-3,601 *$ \\
\hline & $(0,33)$ & $(2,8)$ & $(1,52)$ & $(1,64)$ \\
\hline \multirow[t]{2}{*}{ Auto-cumplimentado } & $-0,424$ & $-3,570$ & $-0,939$ & 1,995 \\
\hline & $(0,38)$ & $(3,19)$ & $(1,73)$ & $(1,86)$ \\
\hline \multirow[t]{2}{*}{ Entrevistador } & $-4,610^{* \star *}$ & $36,345^{* * *}$ & $17,147^{* * *}$ & $14,157^{* * *}$ \\
\hline & $(0,29)$ & $(2,43)$ & $(1,32)$ & $(1,42)$ \\
\hline \multirow[t]{2}{*}{ Constante $^{1}$} & $14,045^{* * *}$ & $49,430^{* * *}$ & $23,700 * * *$ & $58,517^{* * *}$ \\
\hline & $(0,83)$ & $(7,00)$ & $(3,80)$ & $(4,08)$ \\
\hline $\mathrm{R} 2$ & 0,160 & 0,133 & 0,119 & 0,065 \\
\hline$n$ & 2577 & 2577 & 2577 & 2577 \\
\hline
\end{tabular}

1 La base que refleja la constante de esta regresión es una mujer de la muestra con ordenador (W) con menos de 30 años y sin estudios primarios, sin simpatía por un partido político determinado, que considera la ocupación el aspecto más importante para la definición, que no ha pertenecido nunca a una asociación y nació en una población que no es capital de provincia con más de 20.000 habitantes.

${ }^{*} p<0.05,{ }^{* *} p<0.01,{ }^{* * *} p<0.001$

Tabla 3.

Regresiones multinivel de sentencias, subjetividad, anclaje y atribución (segundo nivel: entrevistador).

\begin{tabular}{|c|c|c|c|c|}
\hline & Sentencias & Subjetividad & Anclaje & Atribución \\
\hline \multirow[t]{2}{*}{ Hombre } & $-0,549 * *$ & $-0,466$ & 0,796 & 1,507 \\
\hline & $(0,21)$ & $(1,91)$ & $(0,95)$ & $(1,07)$ \\
\hline \multirow[t]{2}{*}{ Edad 30-39 años } & $-0,223$ & 1,379 & 1,751 & 1,026 \\
\hline & $(0,28)$ & $(2,56)$ & $(1,28)$ & $(1,44)$ \\
\hline \multirow[t]{2}{*}{ Edad 40-49 años } & $-0,368$ & 2,756 & $3,478 * *$ & $-0,134$ \\
\hline & $(0,29)$ & $(2,59)$ & $(1,30)$ & $(1,46)$ \\
\hline \multirow[t]{2}{*}{ Edad 50-59 años } & 0,036 & 2,317 & $5,268 * * *$ & $-2,282$ \\
\hline & $(0,35)$ & $(3,19)$ & $(1,60)$ & $(1,80)$ \\
\hline \multirow[t]{2}{*}{ Edad 60-70 años } & $-0,261$ & $-6,206$ & $9,759 * * *$ & $-7,922 * * *$ \\
\hline & $(0,43)$ & $(3,87)$ & $(1,95)$ & $(2,19)$ \\
\hline \multirow[t]{2}{*}{ Estudios universitarios } & 0,570 * & $-0,014$ & $-1,170$ & $3,003 * *$ \\
\hline & $(0,22)$ & $(2,02)$ & $(1,01)$ & $(1,14)$ \\
\hline \multirow[t]{2}{*}{ Trabajo doméstico } & $-1,008 *$ & $-11,390 *$ & 2,157 & $-1,675$ \\
\hline & $(0,49)$ & $(4,47)$ & $(2,24)$ & $(2,53)$ \\
\hline \multirow[t]{2}{*}{ Voto o simpatía: PP } & 0,658 ** & 2,082 & 0,143 & 1,172 \\
\hline & $(0,25)$ & $(2,25)$ & $(1,13)$ & $(1,28)$ \\
\hline \multirow[t]{2}{*}{ Asociación: activamente } & $0,700 * *$ & $-5,436 *$ & 0,293 & 0,728 \\
\hline & $(0,24)$ & $(2,16)$ & $(1,09)$ & $(1,23)$ \\
\hline \multirow[t]{2}{*}{ Asociación: pertenece } & 0,529 & $-4,754$ & 1,706 & $-1,782$ \\
\hline & $(0,29)$ & $(2,60)$ & $(1,31)$ & $(1,47)$ \\
\hline \multirow[t]{2}{*}{ Auto-cumplimentado } & $-0,072$ & $-0,132$ & $-1,515$ & 3,179 \\
\hline & $(0,38)$ & $(3,36)$ & $(1,75)$ & $(1,96)$ \\
\hline
\end{tabular}




\begin{tabular}{|c|c|c|c|c|}
\hline \multirow[t]{2}{*}{ Entrevistador } & $-4,680$ & 36,928 * & 18,062 & 14,529 \\
\hline & $(3,84)$ & $(14,76)$ & $(19,03)$ & $(15,21)$ \\
\hline \multirow[t]{2}{*}{ Constante } & $15,239 * * *$ & 37,918 * & 25,119 & 55,338 ** \\
\hline & $(3,82)$ & $(15,03)$ & $(18,94)$ & $(15,20)$ \\
\hline \multicolumn{5}{|l|}{ Efectos aleatorios } \\
\hline \multirow[t]{2}{*}{ D. típica(entrevistador) } & $3,792 * * *$ & $14,410^{* * *}$ & $18,816^{* * *}$ & $15,001 * * *$ \\
\hline & $(0,41)$ & $(2,42)$ & $(2,03)$ & $(1,79)$ \\
\hline \multirow[t]{2}{*}{ D. típica(residual) } & $5,098 * * *$ & $46,460 * * *$ & $23,196 * * *$ & $26,163^{* * *}$ \\
\hline & $(0,07)$ & $(0,65)$ & $(0,32)$ & $(0,37)$ \\
\hline
\end{tabular}

1 La base que refleja la constante de esta regresión es una mujer de la muestra con ordenador (W) con menos de 30 años, con menos de estudios universitarios, que no se dedica exclusivamente al trabajo doméstico, ni pertenece a una asociación.

${ }^{*} p<0.05,{ }^{* *} p<0.01,{ }^{* * *} p<0.001$

\section{Discusıón}

Para estudiar la influencia del contexto en la definición que los sujetos damos de nosotros mismos, se ha presentado un modo de análisis de las respuestas al TST basado en cuatro indicadores: el número de enunciados sobre sí mismo que cada persona ofrece, la subjetividad, el número de referencias sociales o anclaje y la atribución, que representa el individualismo de las respuestas.

La hipótesis central de la importancia de la situación en la autodefinición parece confirmarse, en línea con los resultados obtenidos en trabajos anteriores que mostraron cómo las condiciones de administración de la prueba del TST puede influir sobre el resultado (Gardner, Gabriel y Lee 1999; Trafimow, Triandis y Goto 1991). También se sustentan las hipótesis relacionadas con la edad y aquellas en las que está implicado el nivel de estudios. Asimismo, como fue previsto, parece ser importante la trayectoria asociativa del individuo en su autodefinición. Sin embargo, variables como el género, la situación laboral o la ideología, no ofrecen explicación en la naturaleza de las respuestas a la pregunta "¿quién soy yo?".

Nuestros resultados confirman también el predominio de respuestas subconsensuales o individuales frente a las consensuales o grupales, como se viene repitiendo desde los inicios de utilización de la técnica por Kuhn y McPartland (1954). En nuestro caso, esto se confirma tanto en la situación de entrevistador como en la de ordenador. Ahora bien, la variedad de medidas que aportamos nos permite ir más allá de la literatura existente en varios aspectos.

En primer lugar, se aprecia que el número de enunciados de respuesta online es significativamente mayor, en línea con lo esperado, lo que podría ser un indicador de la mayor desinhibición que produce la ausencia de un interlocutor directo.

En segundo lugar, el indicador de subjetividad es significativamente superior en la condición de entrevistador presente, también en línea con lo esperado, pues se reduce la necesidad de aportar información consensual de contexto que resulta evidente en la situación (género, edad, incluso nacionalidad u origen étnico). En ese sentido, podríamos entender que la situación con entrevistador presencial es en sí misma una condición individualizadora, en cuanto interacción cercana en un contexto privado.

En tercer lugar, el indicador de anclaje es también significativamente superior en la condición de entrevistador presencial. Este resultado, difícil de contextualizar con la literatura existente, podría parecer contradictorio con el anterior, pero permite sobre todo descartar que la condición online sea una situación que favorece las respuestas colectivas o sociales en comparación con la condición de entrevistador. Aunque esta última presenta porcentaje de anclaje mayor, ello no implica que en la otra situación contrastada estén ausentes las respuestas sociales, como muestra el hecho de que el $26,6 \%$ de las respuestas contengan referencias sociales.

En cuarto lugar, el indicador de atribución es superior en la situación de entrevista personal, aunque es también bastante alto en la condición online, lo cual confirma la pervivencia de los procesos de individualización en nuestras sociedades más allá de la situación específica, si bien de una manera no indiferente a esos contextos en los que se manifiesta.

Además de probar la esperada importancia de la situación, se descubrió la gran influencia de los entrevistadores en las respuestas, para lo que se introdujo un modelo multinivel en el que estos fueron considerados como efecto aleatorio. De este modo, el efecto de significación del contexto (abstracción hecha de la persona entrevistadora) se reduce a la subjetividad de las respuestas, en el sentido de que en las encuestas realizadas en los domicilios la proporción de respuestas subjetivas es bastante mayor.

Tomados en su conjunto, estos resultados tienen claras implicaciones desde un punto de vista metodológico que podrían tener repercusiones más allá de este caso concreto, en la medida en que la aplicación online de cuestionarios es cada vez más frecuente. En este sentido, si consideramos que en la 
condición autoadministrada se producen más enunciados, pero cifras inferiores en los tres indicadores sustantivos que manejamos, esto podría indicar que la situación ante el ordenador facilita el hecho de responder, si bien no necesariamente de una forma pertinente. Dicho de otro modo, la desinhibición ante la pantalla puede producir respuestas quizá más creativas, pero también con un sentido distinto para el proceso de investigación.

\section{Conclusiones}

Este trabajo constata, como en tantas otras aplicaciones del TST, la expresión de la identidad a través de la pertenencia a grupos con los que compartimos características, a través de la toma de conciencia del otro y la alteridad que ellos nos confiere (Mead 1934; Ricoeur 1990). Sin embargo, puede encontrarse una doble cara en la identidad por la que, siguiendo la tesis de la individuación (Giddens 1991; Habermas 1990), las personas construyen una imagen propia atravesada por la propia caracterización y la autorrealización, que se refleja en el grado de atribución que cada persona refleja en la definición de sí misma.

Para dirimir esta cuestión, el presente trabajo aporta distintas medidas. Atribución y anclaje son indicadores respectivos de la dimensión individualismo versus colectivismo (Hofstede 1980). El caracterizarse mediante un adjetivo calificativo individualiza a la persona, le confiere un grado de una cualidad que le diferencia de otras. En cambio, las referencias colectivas que forman parte del anclaje son las que nos vinculan y nos asemejan a los otros. Frente a otros sistemas de análisis de codificación empleados para el análisis del TST, en el que califican cada sentencia como individual o colectiva, esta solución parte de la base de que ambas no son incompatibles, aunque estén correlacionadas negativamente.

De igual modo, se constata que atribución y subjetividad están muy relacionadas entre sí. Es decir, la inicial división entre respuestas consensuales y subconsensuales se entrecruza con los indicadores de referencia y atribución, especialmente con los de este último. Por ello, analizar el TST mediante el empleo de la dimensión individualismo versus colectivismo puede suplantar en buena medida el uso de la clasificación de las repuestas en función del grado de subjetividad de los enunciados.

Con estos indicadores se ha podido mostrar el efecto de dos distintas situaciones de aplicación del instrumento. Se aprecia que en la situación de entrevista personal tanto las medidas de subjetividad y atribución (individualidad), como las de anclaje (sociabilidad), dan lugar a cifras mayores que en la situación online, siempre en un entorno de predominio de las respuestas individualizadoras. Pero además hemos podido medir, de alguna manera, el efecto concreto de la persona del entrevistador sobre las respuestas.
Así se puede apreciar que el hecho de plantear el TST con múltiples entrevistadores conlleva el riesgo de que se interprete el requerimiento de la definición de modo distinto, y de ahí que las respuestas sean desiguales, no solo según interactuemos o no (situaciones de administración del test ante entrevistador o autoadministrada), sino también en función de la explicación de las instrucciones o expectativas distintas que genera cada persona entrevistadora.

Queda por conocer por qué es tan importante el efecto de los entrevistadores. Podría ser debido a que realizan rutas homogéneas al seleccionar la muestra; podría deberse a sus características sociodemográficas o personales, o bien a diferentes modos de plantear la pregunta o de apoyar la respuesta, como cuando los entrevistadores proporcionan ejemplos diversos - sin atenerse a las instrucciones- a quienes interrogan, si estos preguntan perplejos qué es lo que se pide que contesten ante esta pregunta que tanto atañe a lo personal.

Esto último plantea una interesante controversia en torno a la fiabilidad de las respuestas abiertas en función de quienes las plantean. Deberían emprenderse más investigaciones para estudiar los sesgos que suelen introducirse en estudios de tipo cualitativo, donde no existe un control sobre la aplicación de los instrumentos en el trabajo de campo.

Por otro lado, cabría igualmente ampliar la variedad de situaciones de aplicación del instrumento, para poder dilucidar los factores que intervienen en las diferencias que se aprecian en los presentes resultados, si lo determinante en la entrevista personal es el contexto privado (frente al público), la interacción diádica (frente a la grupal), el entorno personal (frente al impersonal de la pantalla) o cualquier otro elemento.

Por último, la característica sociodemográfica más importante que refleja diferencias en la autodefinición es la edad: las personas de mayor edad producen respuestas más ancladas en el entorno social y recurren menos a los atributos para diferenciarse de los demás. Quedaría por determinar si esto es producto del ciclo vital (si a medida que nos hacemos mayores otorgamos más importancia a las identidades sociales respecto de los referentes personales) o de la generación (si las personas actualmente mayores proceden de un entorno sociocultural más comunitario y menos individualizado), lo que no es posible establecer con estos datos transversales.

En cualquier caso, adquiere sentido el enunciado de que la identidad no es una entidad estática, sino que se construye a lo largo del ciclo vital. Cada vez que interactuamos con una persona o conjunto de personas estamos ajustando nuestra imagen a lo que se espera de nosotros. Si nos encontramos con un desconocido, recrearemos nuestra personalidad en función de las expectativas que imaginemos que el otro tiene de nosotros (Goffman 1959). 
En definitiva, los análisis de las respuestas de estas dos muestras de la población española avalan, a través de las respuestas a la pregunta "¿quién soy yo?", el doble componente personal y social de la identidad; la importancia de la individualización en las auto-imágenes de las personas, especialmente entre personas no mayores, y la enorme influencia que, sobre lo que decimos de nosotros mismos, tienen la situación y las personas ante las que nos presentamos.

\section{Referencias Bibliográficas}

Ashton-James, C.E., W.W. Maddux, A.D. Galinsky y T.L. Chartrand. 2009. "Who I Am Depends on How I Feel: The Role of Affect in the Expression of Culture". Psychological Science, 20 (3): 340-346. https://doi. org/10.1111/j.1467-9280.2009.02299.x

Bajtin, M.M. 1986. Problemas de la poética de Dostoievski. México: F.C.E.

Beck, U. y E. Beck-Gersheim. 2001. Individualization: Institutionalized Individualism and its Social and Political Consequences. London: Sage.

Berger, P. L. y T. Luckmann. 1966. The Social Construction of Reality: A Treatise on the Sociology of Knowledge. Garden City, NY: Anchor Books.

Billig, M. 1987. Arguing and Thinking. Cambridge: Cambridge University Press.

Bruner, J. 1990. Acts of Meaning. Cambridge, MA: Harvard University Press.

Carpenter, S. y Meade-Pruitt, S. M. 2008. "Does the Twenty Statements Test Elicit Self-Concept Aspects that are Most Descriptive?". World Cultures eJournal 16: 1-11. http://escholarship.org/uc/item/466355d4

Del Prado, A.M. et al. 2007. "Culture, Method, and the Content of Self-Concepts: Testing Trait, Individual-self-primacy, and Cultural Psychology Perspectives". Journal of Research in Personality 41: 1119-1160. https://doi. org/10.1016\%2Fj.jrp.2007.02.002

Deschamps, J.C. y T. Devos. 1996. "Relaciones entre identidad personal e identidad social." Pp. 39-56 en Identidad social. Aproximaciones psicosociales a los grupos y a las relaciones entre grupos, compilado por J. F. Morales, D. Páez, J. C. Deschamps y S. Worchel. Valencia: Promolibro.

Dhawan, N., I.J. Roseman, R.K. Naidu, K. Thapa, y S.I. Rettek. 1995. "Self-concepts Across Two Cultures". Journal of Cross-Cultural Psychology 26 (6): 606-621. https://doi. org/10.1177/002202219502600606

Driver, E. D. 1969. "Self-conceptions in India and the United States: A Cross-cultural Validation of the Twenty Statements Test". The Sociological Quarterly 10: 341-359. https://doi.org/10.1111/j.1533-8525.1969. tb01297.x

Dubar, C. 2002. La crisis de las identidades: La interpretación de una mutación. Barcelona: Bellaterra.

Eaton, L. y J. Louw. 2000. "Culture and Self in South Africa: Individualism-collectivism Predictions". The Journal of Social Psychology 140: 210-217. https://doi. org/10.1080/00224540009600461

Emanuel, L., G.J. Neil, C. Bevan, D. Stanton Fraser, S.V. Stevenage, M.T. Whitty y S. Jamison-Powell 2014. "Who am I? Representing the Self Offline and in Different Online Contexts". Computers in Human Behavior 41: 146-152. https://doi.org/10.1016/j. chb.2014.09.018

\section{Agradecimientos}

La investigación objeto de esta comunicación se financia con fondos del Programa Nacional del Plan de Investigación Científica, Desarrollo e Innovación Tecnológica $(I+D+I)$ del Ministerio de Economía y Competitividad (CSO2011-27005, CS-2013-49278EXP y CSO2015-65094-P).

Escobar, M. 1983. "La autoidentidad. Problemas metodológicos del 'Twenty Statements Test'". Revista Española de Investigaciones Sociológicas 23: 35-51. https://doi. org/10.2307/40183016

Escobar, M. 1987. La identidad social del parado. Madrid: Ministerio de Trabajo y Seguridad Social.

Escobar, M., E. Montes y M. Sánchez-Sierra. 2015. "Sentido, referencia y atribución en las descripciones personales. Una nueva perspectiva del TST". Revista Española de Sociología 24: 25-41.

Escobar, M., y H. Román. 2011. "La presentación del yo en el ciberespacio. Un análisis de las autodefiniciones personales en blogs y redes sociales". Revista de Psicología Social 26 (2): 207-222. https://doi.org//10. 1174/021347411795448947

Gardner, W. L., S. Gabriel y A. Y. Lee. 1999. ““”” Value Freedom, but "we" Value Relationships: Self-Construal Priming Mirrors Cultural Differences in Judgment". Psychological Science 10: 321-326. https://doi.org/10.1111/1467-9280.00162

Gergen, K. J. 1991. The Saturated Self. New York: Basic Books.

Giddens, A. 1991. Modernity and Self-identity. Stanford, CA: Stanford University Press.

Goffman, E. 1959. The Presentation of Self in the Everyday Life. London: Penguin Books.

Goffman, E. 1963. Stigma: Notes on the Management of Spoiled Identity. Englewood Cliffs: Prentice-Hall.

Goffman, E. 1967. Interaction Ritual: Essays in Face-to-face Behavior. Chicago: Aldine.

Gómez, A. y A. Vázquez. 2015. "Identidad personal e identidad social. ¿Dos procesos diferentes o uno solo?". Revista de Psicología Social 30 (3): 468-480. https:// doi.org/10.1080/02134748.2015.1065091

Grace, S. L. y K.M. Cramer. 2002. "Sense of Self in the New Millennium: Male and Female Student Responses to the TST". Social Behavior and Personality 30: 271280. https://doi.org/10.2224/sbp.2002.30.3.271

Greenwald, A. y A. Pratkanis. 1984. "The Self". Pp. 129-178 in Handbook of Social Cognition, editado por R. S. Wyer y T. K. Srull. Hillsdale: Erlbaum.

Habermas, J. 1990. Pensamiento Postmetafísico. Madrid: Taurus.

Hermans, H. J. M. y T. Gieser. 2012. Handbook of Dialogical Self Theory. Cambridge: Cambridge University Press.

Hermans, H. J. M., A. Konopka, A. Oosterwegel y P. Zomer. 2016. "Fields of Tension in a Boundary-Crossing World: Towards a Democratic Organization of the Self". Integrative Psychological and Behavioral Science 51: 505-535. https://doi.org/10.1007/s12124-016-9370-6

Hofstede, G. 1980. Culture's Consequences, Beverly Hills: Sage.

Isbell, L., J. McCabe, K. Burns y E. Lair. 2013. "Who am I?: The Influence of Affect on the Working Self-concept". Cognition and Emotion 27: 1073-1090. https:/doi.org/1 $0.1080 / 02699931.2013 .765388$ 
James, W. 1890. The Principles of Psychology. New York: H. Holt and company.

Kanagawa, C., S.E. Cross y H. R. Markus. 2001. "Who Am I'. The Cultural Psychology of the Conceptual Self." Society for Personality and Social Psychology 27: 90103. https://doi.org/10.1177/0146167201271008

Kuhn, M. H. y T.S. McPartland. 1954. "An Empirical Investigation of Self-attitudes". American Sociological Review 19: 68-76. https://doi.org/10.2307/2088175

Lalljee, M. y R. Angelova. 1995. "Person Description in India, Britain and Bulgaria". Journal of Cross-Cultural Psychology 26: 645-657. http://journals.sagepub.com/ doi/10.1177/002202219502600608

Lam, M. et al. 2014. "Spontaneous Self-concept among Chinese Undergraduates in Hong Kong". Social Behavior and Personality 42: 1353-1364 https://doi.org/10.2224/sbp.2014.42.8.1353

McCall, G. J. y J. L. Simmons. 1978. Identities and Interactions: An Examination of Human Associations in Everyday Life. New York: Free Press.

McPartland, T. S. 1971. Manual for the Twenty Statements Test. Kansas City, MI: The Greater Kansas City Mental Health Foundation.

Mead, G. H. 1934. Mind, Self, and Society. Chicago: Chicago University Press.

Noppe, I. C. 1983. "A Cognitive-Development Perspective on the Adolescent Self-concept". Journal of Early Adolescence 3: 275-286. https://doi. org/10.1177/0272431683033010

Revilla, J.C. 1998. La identidad personal de los jóvenes: pluralidad y autenticidad. Madrid: Entinema.

Revilla, J.C. 2003. "Los anclajes de la identidad personal". Athenea. Revista de Pensamiento e Investigación Social 4: 54-67. https://doi.org/10.5565/rev/ athenead/v1n4.85

Rhee, E., J.S. Uleman, H.K. Lee y R.J. Roman. 1995. "Spontaneous Self-descriptions and Ethnic Identities in Individualistic and Collective Cultures". Journal of Personality and Social Psychology 69 (1): 142-152. https://doi.org/10.1037/0022-3514.69.1.142

Ricoeur, P. 1990. Soi même comme un autre. Paris: Editions du Seuil.
Sampson, E.E. 1989. "The Deconstruction of the Self". Pp. 1-19 in Texts of Identity, editado por J. Shotter y K.J. Gergen. London: Sage.

Santamaría, A., M.L. de la Mata, T.G.B. Hansen y L. Ruiz. 2010. "Cultural Self-construals of Mexican, Spanish, and Danish College Students: beyond Independent and Interdependent Self". Journal of Cross-Cultural Psychology 41: 471-477. https://doi. org/10.1177/0022022109359694

Schwirian, K.P. 1964. "Variation in the Structure of the KhunMcPartland Twenty Statements Test and Related Responses Differences". The Sociological Quarterly 5: 47-59. https://doi.org/10.1111/j.1533-8525.1964.tb02255.x

Sennett, R. 1998. The Corrosion of Character. New York: W.W.Norton \& Company.

Somech, A. 2000. "The Independent and the Interdependent Selves: Different Meanings in Different Cultures". International Journal of Intercultural Relations 24: 161172. https://doi.org/10.1016/S0147-1767(99)00030-9

Trafimow, D., E.S. Silverman, R. Mei-Tai Fan y J. Shui Fun Law. 1997. "The Effects of Language and Priming on the Relative Accessibility of the Private Self and the Collective self". Journal of CrossCultural Psychology 28 (1): 107-123. https://doi. org/10.1177/0022022197281007

Trafimow, D., H.C. Triandis y S.G. Goto. 1991. "Some Test of Distinction between the Private Self and the Collective Self'. Journal of Personality and Social Psychology 60 (5): 649-655. https://doi.org/10.1037/0022-3514.60.5.649

Triandis, H.C. 1989. "The Self and Social Behavior in Differing Cultural Contexts". Psychological Review 96 (3): 506520. https://doi.org/10.1037/0033-295X.96.3.506

Vindhya, U. 2012. "Guns and Roses: Collective Identity Processes of Women Activist in India". Feminism \& Psychology 22: 183-203. https://doi. org/10.1177/0959353512437160

Wagner, P. 2001. Theorizing Modernity. London: Sage.

Watkins, D. y A. Gerong. 1999. "Language of Response and the Spontaneous Self-concept". Journal of Cross-Cultural Psychology 30: 115-121. https://doi. org/10.1177/0022022199030001007

MODESTO ESCOBAR es doctor en Sociología por la Universidad Complutense de Madrid y catedrático en el Departamento de Sociología y Comunicación de la Facultad de Ciencias Sociales de la Universidad de Salamanca, es autor de libros como La identidad social del parado, El análisis de segmentación. Análisis de datos con Stata, Los pronósticos electorales con encuesta y Socioestadística. Asimismo, ha coeditado El análisis de la realidad social. Métodos y técnicas de investigación y ha escrito, entre otros artículos en revistas de sociología, "La autoidentidad. Problemas metodológicos del Twenty Statement Test", "La presentación del self en el ciberespacio" y "Sentido, referencia y atribución en las descripciones personales".

JUAN CARLOS REVILLA es doctor en Sociología por la Universidad Complutense de Madrid, profesor titular del área de Psicología Social en el Departamento de Antropología Social y Psicología Social (Facultad de Ciencias Políticas y Sociología, UCM) y miembro de EGECO y TRANSOC. Es autor de numerosas publicaciones nacionales e internacionales en temas de identidad, estudios críticos del trabajo, juventud y violencia. Ha sido coordinador nacional de los proyectos europeos SPHERE y RESCuE (70 Programa Marco). Entre sus publicaciones destaca: "La identidad personal de los jóvenes: pluralidad y autenticidad" (Entinema, 1998), "Los anclajes de la identidad personal" (Athenea, 2003), "Las lógicas de control organizacional en el siglo XXI" (REIS, 2011), "Collective identities in the age of restructuring" (International Sociology, 2013) y "La articulación de las identidades sociales colectivas" (Papeles del CEIC, 2015).

MARINA SÁNCHEZ-SIERRA RAMOS es socióloga por la Universidad de Salamanca, ha trabajado en distintas empresas privadas de consultoría. Asimismo, ha sido investigadora en el Departamento de Sociología y Comunicación de la Facultad de Ciencias Sociales de la Universidad de Salamanca en temas relacionados con la identidad social y la implementación de la igualdad de género en la Administración Pública. Es coautora del artículo "Sentido, referencia y atribución en las descripciones personales" y una de las fundadoras de SOCYL, asociación profesional de sociología dedicada a promover y dar mayor visibilidad a la profesión. 